\title{
Regulation of LCoR and RIP140 expression in cervical intraepithelial neoplasia and correlation with CIN progression and dedifferentiation
}

\author{
Tilman L. R. Vogelsang ${ }^{1}$ - Elisa Schmoeckel ${ }^{3}$. Christina Kuhn ${ }^{1} \cdot$ Thomas Blankenstein $^{1} \cdot$ Mina Temelkov $^{1}$. \\ Helene Heidegger ${ }^{1}$. Theresa Maria Kolben ${ }^{1} \cdot$ Thomas Kolben $^{1} \cdot$ Sven Mahner ${ }^{1}$. Doris Mayr ${ }^{3}$. Udo Jeschke ${ }^{1,2}$. \\ Aurelia Vattai $^{1}$
}

Received: 10 February 2020 / Accepted: 3 March 2020 / Published online: 10 March 2020

(c) The Author(s) 2020

\begin{abstract}
Purpose Ligand-dependent corepressor (LCoR) and receptor-interacting protein 140 (RIP140/NRIP1) play an important role in the regulation of multiple oncogenic signaling pathways and the development of cancer. LCoR and RIP140 form a nuclear complex in breast cancer cells and are of prognostic value in further prostate and cervical cancer. The purpose of this study was to analyze the regulation of these proteins in the development of cervical intraepithelial neoplasia (CIN I-III). Methods Immunohistochemical analysis was obtained to quantify RIP140 and LCoR expression in formalin-fixed paraffin embedded tissue sections of cervical intraepithelial neoplasia samples. Tissue $(n=94)$ was collected from patients treated in the Department of Gynecology and Obstetrics, Ludwig-Maximilians-University of Munich, Germany, between 2002 and 2014. Correlations of expression levels with clinical outcome were carried out to assess for prognostic relevance in patients with CIN2 progression. Kruskal-Wallis test and Mann-Whitney $U$ test were used for data analysis.

Results Nuclear LCoR overexpression correlates significantly with CIN II progression. Nuclear RIP140 expression significantly increases and nuclear LCoR expression decreases with higher grading of cervical intraepithelial neoplasia. Cytoplasmic RIP140 expression is significantly higher in CIN III than in CIN I or CIN II.

Conclusion A decrease of nuclear LCoR expression in line with an increase of dedifferentiation of CIN can be observed. Nuclear LCoR overexpression correlates with CIN II progression indicating a prognostic value of LCoR in cervical intraepithelial neoplasia. Nuclear and cytoplasmic RIP140 expression increases significantly with higher grading of cervical intraepithelial neoplasia underlining its potential role in the development of pre-cancerous lesions. These findings support the relevance of LCoR and RIP140 in the tumorigenesis indicating a possible role of LCoR and RIP140 as targets for novel therapeutic approaches in cervical intraepithelial neoplasia and cervical cancer.
\end{abstract}

Keywords RIP140 $\cdot \mathrm{LCoR} \cdot \mathrm{CIN} \cdot$ Cervical intraepithelial neoplasia $\cdot$ Cervical cancer

$\begin{array}{ll}\text { Abbreviations } \\ \text { CIN } & \text { Cervical intraepithelial neoplasia } \\ \text { LCoR } & \text { Ligand-dependent corepressor } \\ \text { RIP140 } & \text { Receptor-interacting protein of } 140 \mathrm{kDa} \\ \text { NRIP1 } & \begin{array}{l}\text { Nuclear receptor-interacting protein } 1 \\ (=\text { RIP140) }\end{array} \\ \text { Er } \alpha & \text { Estrogen receptor } \alpha \\ \text { KLF6 } & \text { Krüppel-like factor } 6 \\ \text { pRb } & \text { Retinoblastoma protein } \\ \text { OS } & \text { Overall survival }\end{array}$

Udo Jeschke

udo.jeschke@med.uni-muenchen.de

Extended author information available on the last page of the article

\section{Introduction}

Cervical cancer is the fourth most common cancer in females worldwide with more than 500,000 new cases each year (World Health Organization 2019, January 24). Furthermore, it is causing $7.5 \%$ of all cancer deaths in women (Ferlay et al. 2019). Due to routine cervical cancer screening methods such as HPV testing and cervical cytology (i.e. Pap smear test), the incidence of cervical cancer has decreased strongly, implicating the importance of the detection and treatment of pre-cancerous lesions, cervical intraepithelial neoplasia (CIN) (Schiffman and Wentzensen 2013). CINs are categorized into three grades (CIN I-III) depending on the amount of dysplastic epithelium involved. The major leading cause for the development of CIN and 
ultimately invasive cancer is a persistent infection with highrisk Human Papillomavirus (HR-HPV) (Schiffman et al. 2011). When expressed, the viral oncoprotein E6 disturbs the cell cycle by binding and degrading the tumor suppressor protein p53 (Gupta et al. 2003; Scheffner et al. 1990). The viral oncoprotein E7 disturbs the cell cycle by binding and degrading the retinoblastoma protein $(\mathrm{pRb})$ and triggering E2F dissociation leading to proliferation of the cell and inhibition of cell death and differentiation (Chellappan et al. 1992; Wise-Draper and Wells 2008).

In the last 5-9 years, incidence of cervical intraepithelial neoplasia grades II and III has decreased by $30-50 \%$ due to HPV vaccination while incidence of CIN II and III has increased significantly by $19-23 \%$ in patients without HPV vaccination (Drolet et al. 2019).

Ligand dependent corepressor (LCoR) was initially described as a coregulator of estrogen receptor $\alpha(E R \alpha)$ (Fernandes et al. 2003). Recent studies suggest its interaction with various transcription factors such as Krüppel-like factor 6 (KLF6) (Calderon et al. 2012) and peroxisome proliferator-activated receptor $\gamma$ (PPAR $\gamma$ ) (Shalom-Barak et al. 2018). It acts by recruiting histone deacetylases and C-terminal binding proteins (Palijan et al. 2009a, b). Asim and colleagues could show that LCoR inhibits prostate cancer growth in a xenograft mouse model via co-repression of activated androgen receptor (AR) (Asim et al. 2011).

Receptor-interacting protein of $140 \mathrm{kDa}$ (RIP140), also known as nuclear receptor-interacting protein 1 (NRIP1), is described as a transcriptional coregulator of agonistliganded ER $\alpha$. Similar to LCoR, it functions by recruiting histone deacetylases and $\mathrm{C}$-terminal binding proteins (Castet et al. 2004; Christian et al. 2004). RIP140 acts mostly as a co-repressor of multiple nuclear receptors and transcription factors and limits their transactivation (Augereau et al. 2006a, b; Cavailles et al. 1995).

RIP140 plays an important role in the progression and development of cancer (Aziz et al. 2015; Ghoussaini et al. 2012; Lapierre et al. 2014, 2015; Lei et al. 2015). In colon cancer, RIP140 is involved in Wnt-signaling and has a negative effect on $\mathrm{Wnt} / \beta$-Catenin target genes and thereby inhibits cell proliferation, epithelial cell progression, and tumor growth (Lapierre et al. 2014, 2015). Direct interaction between RIP140 and E2F1 in breast cancer cell lines results in a repression of E2F1 target genes and could regulate cell proliferation (Docquier et al. 2010). Furthermore, RIP140 is essential for repressive activity of LCoR in breast cancer cell proliferation. LCoR overexpression and parallel downregulation of RIP140 mRNA leads to an increase in cell proliferation in breast cancer cell lines (Jalaguier et al. 2017). Low LCoR and RIP140 gene expression levels were associated with shorter overall survival (OS) in patients diagnosed with breast cancer (Jalaguier et al. 2017). Conversely, in a recent study we showed that RIP140 overexpression was associated with significant shorter overall survival of cervical cancer patients. RIP140 is not a significant negative prognosticator if LCoR expression is low (Vattai et al. 2017).

RIP140 and LCoR recruit similar cofactors implicated in transcriptional co-repression suggesting many parallels in their mechanism of action (White et al. 2004). Both RIP140 and LCoR bind to agonist-bound ligand binding domains (LBD), blocking coactivation in vivo (White et al. 2004). Multiple function and structure studies have displayed that RIP140 and LCoR recognize the same coactivator binding pockets of nuclear receptor LBDs (White et al. 2004).

Aim of this study was to analyze the expression of LCoR and RIP140 in cervical intraepithelial neoplasia grade I, II and III (CIN I-III) and the correlation of their expression regarding the progression of cervical dysplasia.

\section{Methods}

Formalin-fixed paraffin embedded samples of 94 patients who had been treated at the Department of Gynecology and Obstetrics at Ludwig-Maximilians-University Munich, Germany, between 2002 and 2014 were included in this study. 81 slides could be obtained for analysis and 13 slides were not considered for analysis due to failed staining or no CIN staining on the slide. Patients were either diagnosed with CIN I $(n=38)$, CIN II $(n=26)$ or CIN III $(n=17)$. There has been no preselection of the patients. Histopathological grade of dysplasia and diagnosis were confirmed by a second gynecological pathologist. For progression analysis in CIN II samples, only patients with a follow-up visit and a histologically confirmed regress $(n=7)$ or progress $(n=17)$ were included. On their first visit all patients were tested positive for high risk Human Papillomavirus (Hybrid Capture 2, Quiagen). Initially, the tissue analyzed in this study had been collected due to routine histopathological diagnostics. All diagnostic procedures had been carried out beforehand.

\section{Immunohistochemistry}

Immunohistochemical quantification of LCoR and RIP140 expression was obtained in the embedded samples of cervical dysplasia (CIN I-III). Immunohistochemical staining was obtained as described in earlier publications (Hester et al. 2019; Vattai et al. 2017). Tissue samples were surgically generated and instantly fixed in neutral buffered formalin (3.7\%) followed by standardized paraffin bedding. 
Immunohistochemistry was initiated by deparaffinization of the formalin-fixed paraffin embedded tissue slices $(3 \mu \mathrm{m})$ in xylol. Inactivation of endogenous peroxidase was obtained with $3 \% \mathrm{H}_{2} \mathrm{O}_{2}$ in methanol for $20 \mathrm{~min}$ followed by a descending ethanol gradient for rehydration of the slides. Next, a pressure cooker filled with sodium citrate buffer ( $\mathrm{pH}$ 6.0) was used to prepare the tissue for epitope retrieval. To prevent non-specific binding of the primary antibodies, blocking solution was applied. The tissue slides were incubated over night for $16 \mathrm{~h}$ consecutively with the following antibodies: anti-LCoR (polyclonal rabbit IgG, Novus Biologicals, Littleton, USA) and anti-RIP140 (polyclonal rabbit IgG, Sigma Aldrich, St. Louis, USA). Analyzation of the antibody reactivity was obtained with the ZytoChemPlus HRP Polymer System (mouse/rabbit) (Zytomed Systems, Berlin, Germany) according to the manufacturer's protocol. Substrate and chromogen (3,3'-diaminobenzidine DAB; Dako, Glostrup, Denmark) was applied on the samples. Counterstaining was obtained with Mayer's acidic hematoxylin. After dehydrating the slides in an ascending row of ethanol, the slides were cover slipped. Both nuclear and cytoplasmic staining of LCoR and RIP140 were further correlated with EP3 staining which has been carried out and published previously (Hester et al. 2019).

\section{Quantification}

Analyzation of cervical dysplasia tissues was conducted by two different and independent observers using Leitz Diaplan microscope (Leitz, Wetzlar, Germany). To quantify each slide's staining, the semiquantitative immunoreactive score (IRS) was used. Intensity and distribution pattern of the antigen are optically evaluated with the immunoreactive score (IRS) (Remmele and Stegner 1987). It was calculated by multiplying staining intensity ( 0 : none; 1 : weak; 2 : moderate; 3 : strong) with the number of positively stained cells (in \%) (0: no staining, $1:<10 \%$ of the cells; $2: 11-50 \%$; 3 : $51-80 \% ; 4:>80 \%$ ). A scale from 0 (no expression) to 12 (very high expression) was used. Photos were taken with a CCD color camera (JVC, Victor Company of Japan, Japan).

\section{Statistical analysis}

For data analysis IBM SPSS Statistics for Windows, Version 25 , was used. $P$ values $p<0.05$ were considered statistically significant. Comparative analysis between different grades of CIN was obtained using nonparametric Kruskal-Wallis rank-sum test and Mann-Whitney $U$ test. Spearman's rank correlation coefficient was used for correlation analysis. Figures were designed using IBM SPSS Statistics for Windows,
Version 25 as well as Microsoft $®$ PowerPoint for Mac Version 16.30 (19101301).

\section{Results}

\section{Nuclear LCoR expression in CIN grade I-III and correlation analysis with histopathological variables}

Differences in nuclear LCoR expression were examined by comparing LCoR immunoreactive scores (IRS) between the groups of cervical tissue as shown in Fig. 1. While CIN I and CIN II showed a median IRS of four, median IRS in CIN III was two $(p=0.008)$. LCoR expression compared between CIN I and CIN II is not significantly changed $(p=0.088)$. Exemplary staining for all CIN grades is shown in Fig. 1.

For positive nuclear LCoR expression in cervical dysplasia tissue, a significant correlation with cytoplasmic LCoR $(p=0.014$, Spearman Rho 0.270) was detected. Cytoplasmic RIP140 expression was negatively correlated with nuclear LCoR expression ( $p=0.043$; Spearman Rho -0.224$)$.

\section{RIP140 expression in CIN grade I-III}

RIP140 expression was observed in the nucleus as well as the cytoplasm. In both compartments RIP140 expression significantly increased with higher grading of dysplasia as shown in Figs. 2 and 3. While CIN I showed a nuclear RIP140 expression with a median of two, the median in CIN II was five and in CIN III the median IRS was six (Kruskal-Wallis test $p=0.000$ ). Cytoplasmic RIP140 expression in CIN I and CIN II with a median of zero increased significantly to the median of one in CIN III (Kruskal-Wallis test $p=0.001$ ). Exemplary staining for all grades of CIN is shown in Figs. 2 and 3.

Correlation analysis showed that nuclear RIP140 expression correlated positively with cytoplasmic RIP140 ( $p=0.000$; Spearman Rho 0.552). Nuclear RIP140 correlated negatively with EP3 expression ( $p=0.010$; Spearman Rho-0.290) in cervical dysplasia tissue. Cytoplasmic RIP140 expression correlated negatively with EP3 expression $(p=0.001$, Spearman Rho-0.365).

\section{Nuclear LCoR expression and progression of CIN}

We compared nuclear LCoR expression between CIN II cases with histologically confirmed progress or regress to evaluate if LCoR expression is a prognostic marker for a progressive or regressive course in CIN. The median IRS of CIN II that showed a regressive course was three whereas 

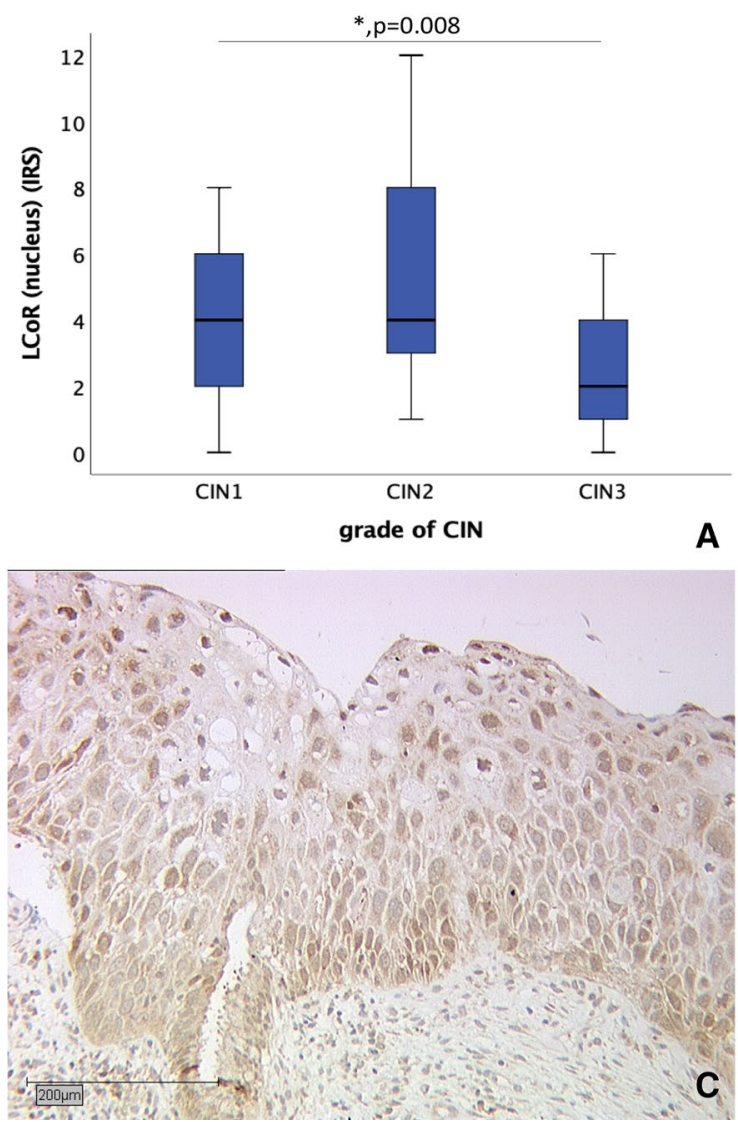

Fig. 1 Correlation of nuclear LCoR expression (IRS) with grade of dysplasia. a Boxplot of nuclear LCoR expression and grade of dysplasia. b CIN I $(n=37)$ with nuclear LCoR IRS of 4 ; magnifi-

the median IRS of CIN II with a progressive course was six (Fig. 4, Kruskal-Wallis test $p=0.004$ ).

\section{Discussion}

In a previous study we could show that patients with cervical cancer expressing low levels of LCoR and RIP140 correlate with a better overall survival than patients expressing high levels of RIP140 (Vattai et al. 2017). RIP140 is an independent predictor of poor OS in patients with cervical cancer (Vattai et al. 2017). In the current study we could show that nuclear RIP140 expression increases significantly with the cervical dysplasia grade. In line with our findings, RIP140 plays a role in different molecular pathways that affect the development of cervical cancer such as the estrogen receptor signaling (Lapierre et al. 2015). Elevated estrogen levels lead to a higher risk of cervical intraepithelial neoplasia as well as cervical cancer in HPV-infected patients (Ramachandran 2017).
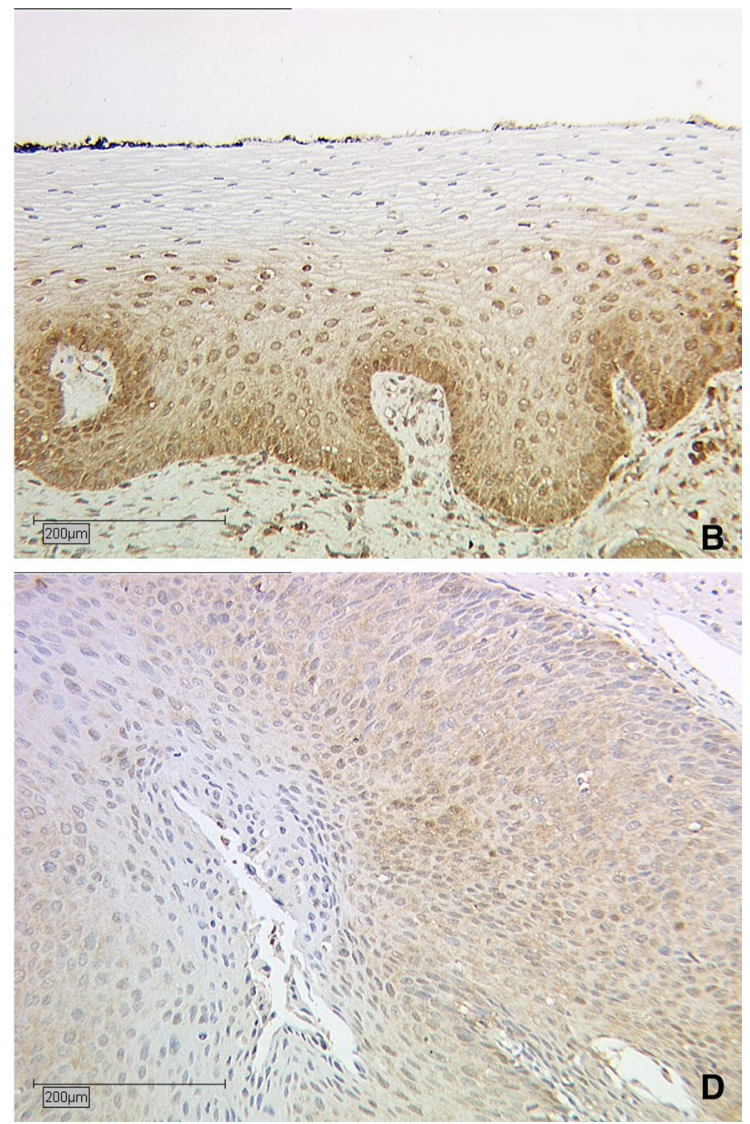

cation $\times 10$. c CIN II $(n=26)$ with nuclear LCoR IRS of 3; magnification $\times 10$. d CIN III $(n=16)$ with nuclear LCoR IRS of 2 ; magnification $\times 10$

Besides its influence on estrogen receptor signaling, RIP140 represses transactivation of E2F1 and inhibits expression of several E2F1 target genes in breast cancer cell lines (Docquier et al. 2010). E2F1 is a transcriptional activator that plays an essential role in the regulation of cell proliferation, apoptosis, G1/S transition and S-phase entry during the cell cycle (Chen et al. 2009; Dimova and Dyson 2005). It can bind to and is regulated by the tumor suppressor protein retinoblastoma (pRb) (McNair et al. 2018). Phosphorylation of $\mathrm{pRb}$ by $\mathrm{G} 2-\mathrm{M}$ and S-phase cyclin dependent kinases releases E2F1 and allows it to transcribe its target genes resulting in cell cycle progression (Weinberg 1995). The degradation of E2F repressor pRb by the HPV oncoprotein $\mathrm{E} 7$ via the ubiquitin-proteasome pathway results in activation of E2F-regulated genes and consequently deregulates the progression through the G1 phase of the cell cycle (Boyer et al. 1996; Rosty et al. 2005). In cervical cancer, E2F1 expression is significantly increased suggesting that genes which are involved in invasive cervical carcinoma are regulated by E2F (Rosty et al. 2005; Srivastava et al. 2014). 

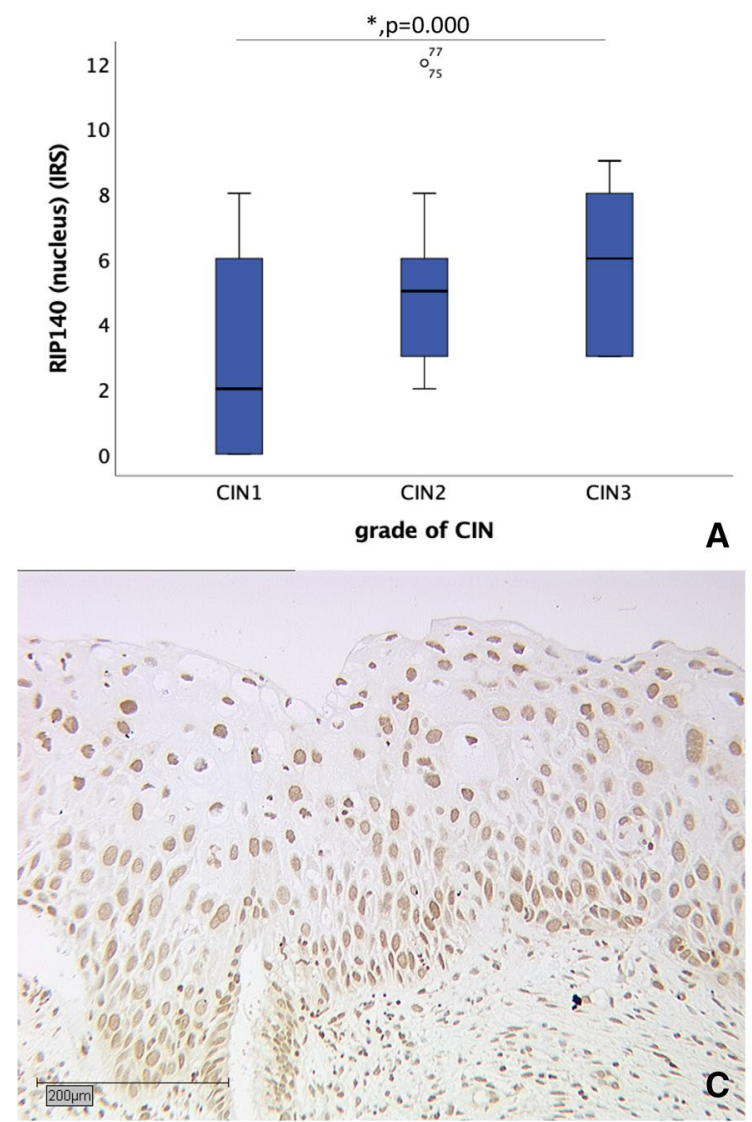

Fig. 2 Correlation of nuclear RIP140 expression (IRS) with grade of dysplasia. a Boxplot of nuclear RIP140 expression and grade of dysplasia. b CIN I $(n=38)$ with nuclear RIP140 IRS of 1 ; magnifica-

Another pathway influenced by RIP140 is Wnt/ $\beta$-catenin signaling which is involved in cancer progression. Lapierre et al. (2014) showed a suppressive effect of RIP140 on $\mathrm{Wnt} / \beta$-catenin target genes in colon cancer. This stands in contrast to the previously described role of RIP140 in cervical and breast cancer and to our results in CIN indicating the complexity of RIP140 regulation (Aziz et al. 2015; Vattai et al. 2017). The Wnt/ $\beta$-catenin signaling pathway has been described in HPV-related tumors implicating potential mechanisms by which the viral oncoproteins E6 and E7 activate this pathway (Bello et al. 2015).

In CIN III, cytoplasmic RIP140 expression is significantly higher than in CIN I or CIN II. Nucleo-cytoplasmic shuttling or a higher transcription followed by modification of RIP140 might explain the cytoplasmic increase. After transcription of genes in the nucleus, proteins are transported to the cytoplasm for translation and modification (Fu et al. 2018). For shuttling, nuclear pore complexes (NPCs) selectively transport cargoes across the nuclear envelope (Alber
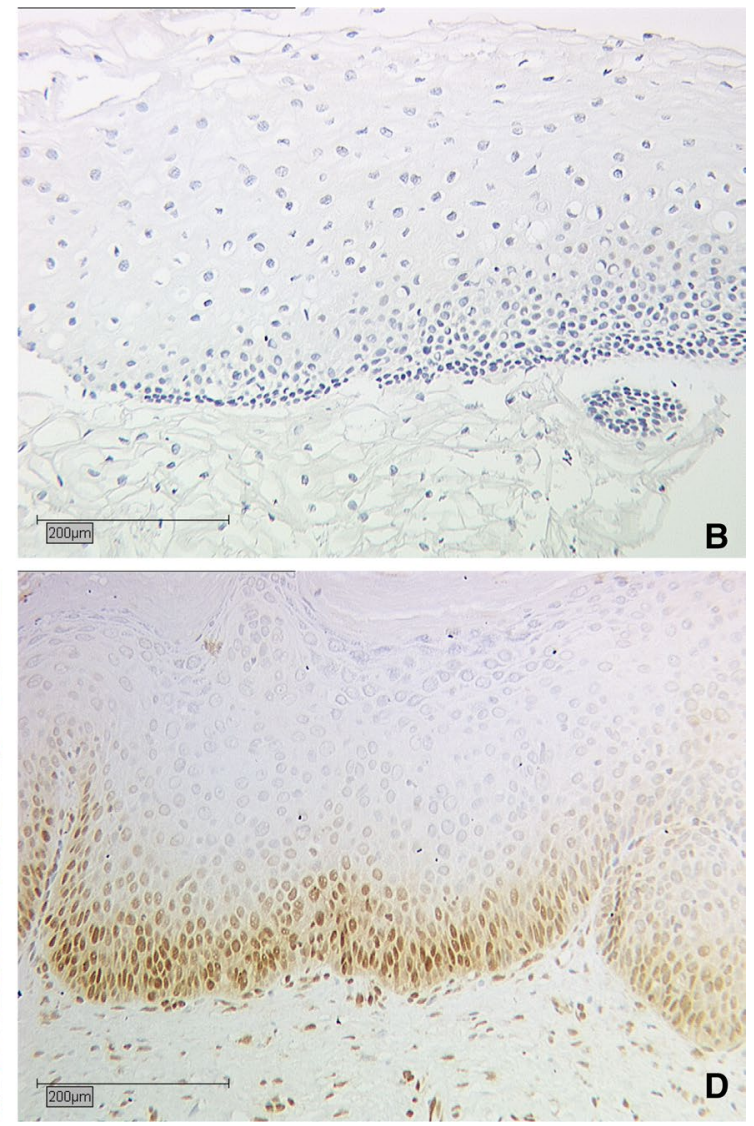

tion $\times 10$. $\mathbf{c}$ CIN II $(n=26)$ with nuclear RIP140 IRS of six; magnification $\times 10$. d CIN III $(n=17)$ with nuclear RIP140 IRS of six; magnification $\times 10$

et al. 2007). Nucleo-cytoplasmic shuttling plays an important role in activity of proteins, signaling pathways, and thereby tumorigenesis (Shreberk-Shaked and Oren 2019). Post-translational modifications such as lysine acetylation (Vo et al. 2001) or conjugation to Vitamin-B6 (Huq et al. 2007) might play a role in nucleo-cytoplasmic shuttling.

LCoR is described as a tumor suppressor in prostate cancer and an inhibitor of cell growth in prostatic cancer cells (Asim et al. 2011). In breast cancer cell lines, LCoR is regulated by RIP140 and inhibits cell proliferation. Jalaguier and colleagues (2017) could show that LCoR mRNA is expressed higher in breast cancer cell lines than in normal samples. In this study, we could show that high nuclear LCoR expression correlates significantly with CIN II progression. High LCoR expression might thereby lead to a higher grade of dysplasia and towards tumorigenesis. Interestingly, high LCoR expression furthermore correlates significantly with low dysplasia grade. In general, $50 \%$ of histologically confirmed CIN II lesions show a regressive 

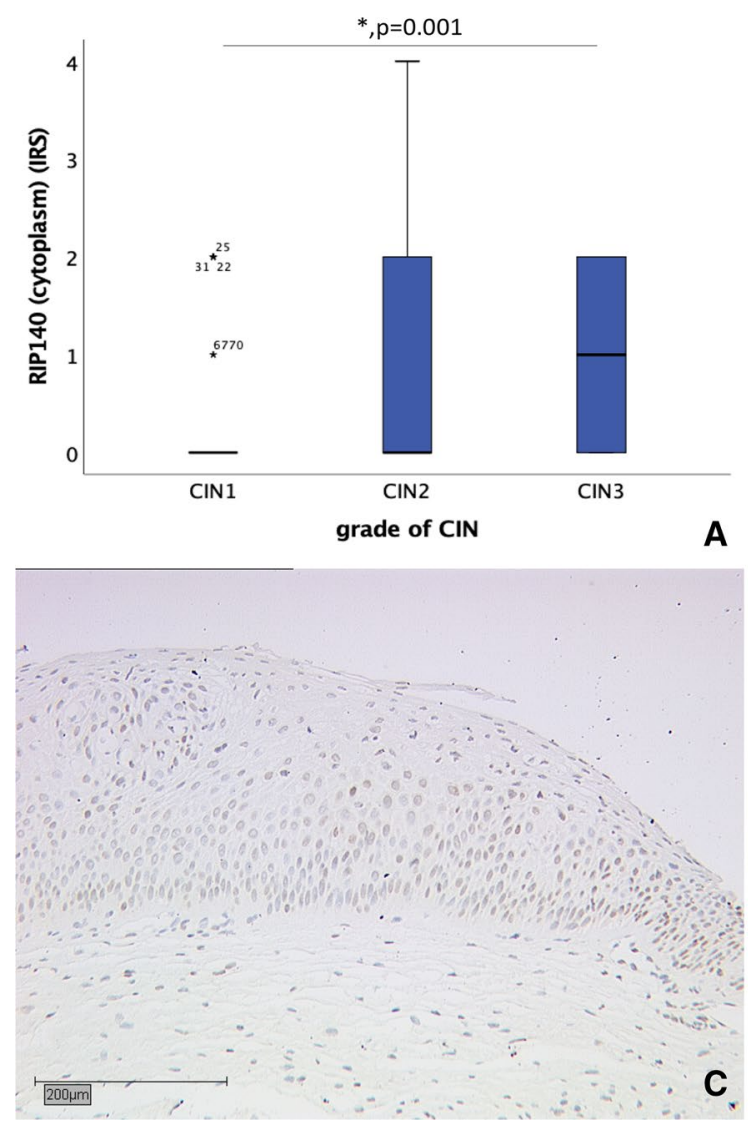

Fig. 3 Correlation of cytoplasmic RIP140 expression (IRS) with grade of dysplasia. a Boxplot of cytoplasmic RIP140 expression and grade of dysplasia. b CIN I $(n=38)$ with cytoplasmic RIP140 IRS

course while only $18 \%$ progress to CIN III or worse within 2 years of surveillance (Tainio et al. 2018). Cervical dysplasia is common in young women and it has been controversially discussed whether or not CIN II is an indication for surgical treatment since loop electrosurgical excision procedure (LEEP) is associated with a significant higher risk of premature birth in following pregnancies (Frega et al. 2018). Therefore, it is of high importance to differentiate between a potentially progressive and regressive CIN II.

Correlations of LCoR and RIP140 expression have been described in studies on breast, cervical, and gastrointestinal cancer (Jalaguier et al. 2017; Triki et al. 2017; Vattai et al. 2017). In our study, we detected a negative correlation
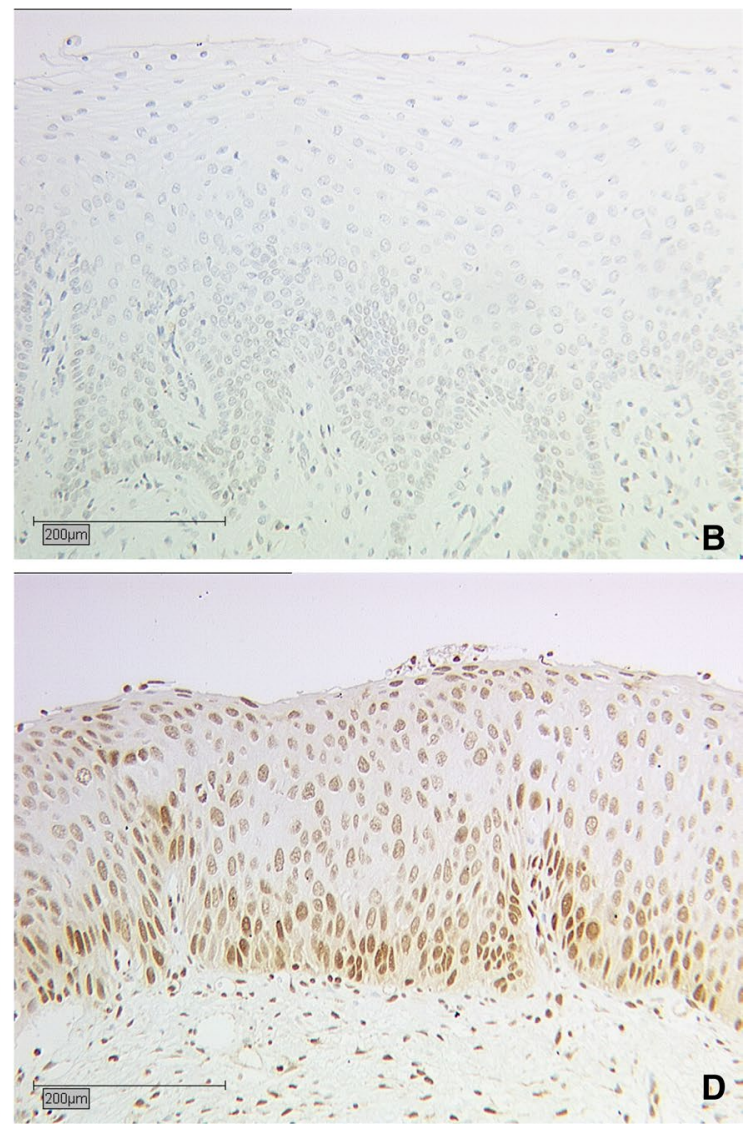

of 0 ; magnification $\times 25$. $\mathbf{c}$ CIN II $(n=26)$ with cytoplasmic RIP140 IRS of zero; magnification $\times 10$. d CIN III $(n=17)$ with cytoplasmic RIP140 IRS of two; magnification $\times 10$

between nuclear LCoR and cytoplasmic RIP140 expression $(p=0.005)$. Correlation of nuclear RIP140 and nuclear LCoR expression was not significant.

In conclusion, in our hypothesis generating study we observed that RIP140 as well as LCoR are expressed differently in all grades of cervical intraepithelial neoplasia, with the exception of LCoR expression compared between CIN I and CIN II, suggesting that LCoR and RIP140 play a relevant role in carcinogenesis of cervical cancer. Additionally, LCoR expression appears to be a marker for CIN II progression. Further experiments are required to analyze whether LCoR can be considered as an additional diagnostic factor to help in the decision-making process regarding non-surgical treatment eligibility of CIN II patients. 


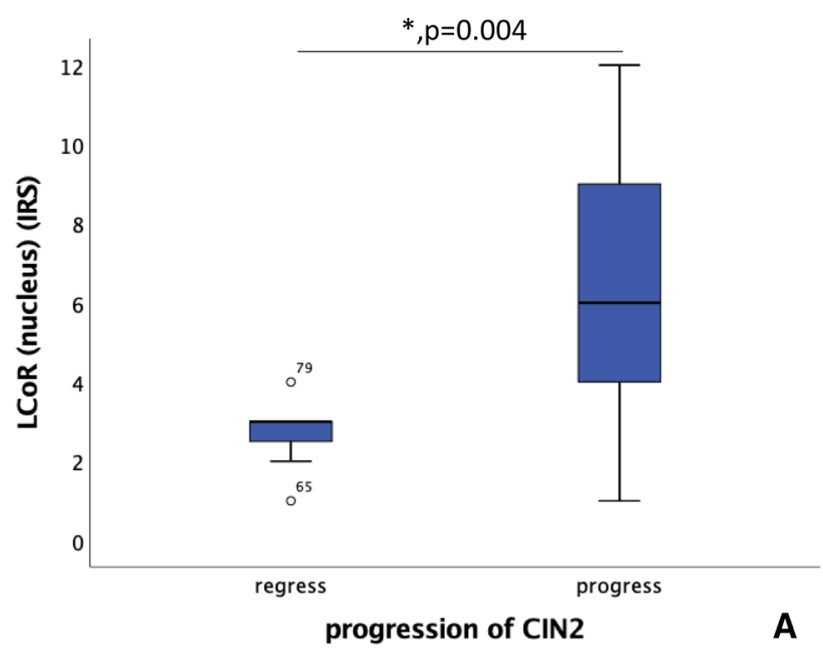

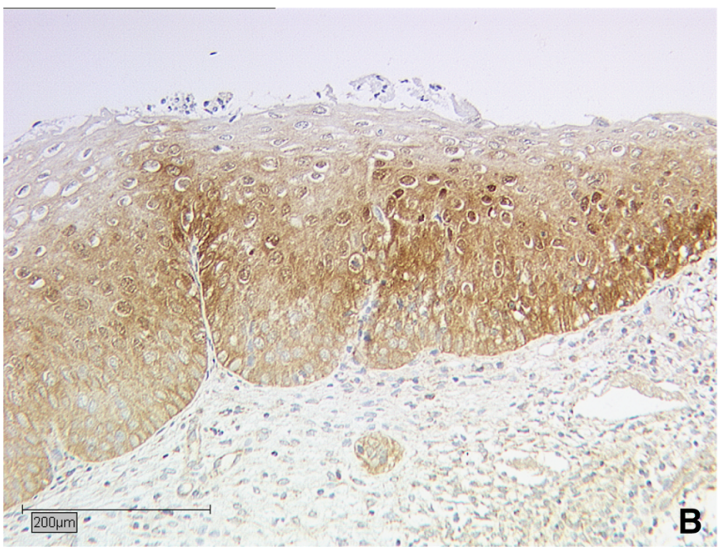

Fig. 4 Correlation of nuclear LCoR expression (IRS) with CIN2 progression. a Boxplot of nuclear LCoR expression and CIN2 progression. b CIN II with regressive course $(n=7)$ with nuclear LCoR IRS

Acknowledgements Open Access funding provided by Projekt DEAL.

Funding T.L.R.V and A.V. have been funded for the study by the structured promotion program of the Ludwig-Maximilians University of Munich, "Molecular and clinically translational Medicine".

Data availability The datasets generated and analyzed during the current study are available from the correspondent author on reasonable request.

\section{Compliance with ethical standards}

Conflict of interest T.M.K. is employed at and is holding stocks in Roche AG. T.K.'s relative works for Roche AG and he is holding stocks in Roche AG. S.M. receives grants from Roche AG, PharmaMar, Tesaro, MEDAC and AstraZeneca and reimbursements and honoraria from Roche AG, PharmaMar, Clovis, Tesaro, AbbVie, SensorKinesis, MEDAC, AstraZeneca, Novartis and MSD. S.M. receives research support, honoraria, travel expenses and advisory board from AstraZeneca, Clovis, AddVie, MEDAC, MSD, Novartis, PharmaMar, Roche AG, SensorKinesis, Tesaro, GSK and Teva. All other authors declare that they have no conflicts of interest.

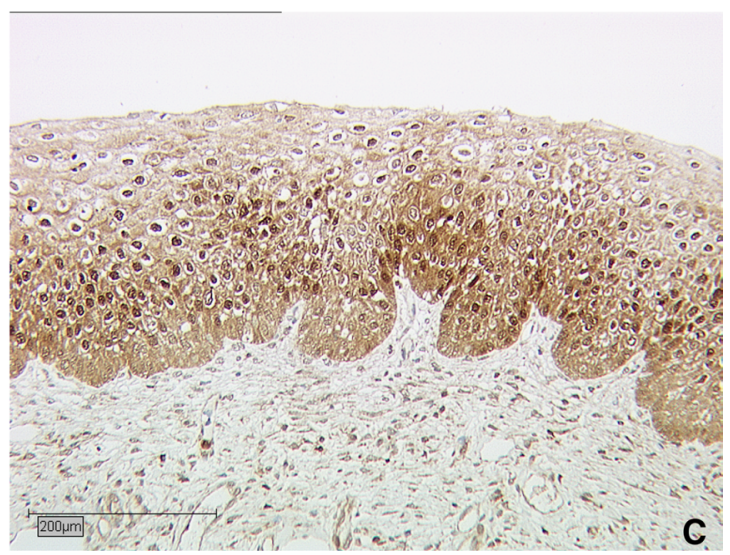

of three; magnification $\times 10$. $\mathbf{c}$ CIN II with progressive course $(n=17)$ with nuclear LCoR IRS of nine; magnification $\times 10$

Ethical approval All patients gave informed consent prior to study participation. All procedures were performed according to the ethical standards of the institutional and/or national research committee and with the declaration of Helsinki of 1964 and its later amendments. This study was approved by the local ethics committee of LudwigMaximilians-University Munich, Germany (167-14).

Informed consent Informed consent was obtained from all individual participants included in this study.

Open Access This article is licensed under a Creative Commons Attribution 4.0 International License, which permits use, sharing, adaptation, distribution and reproduction in any medium or format, as long as you give appropriate credit to the original author(s) and the source, provide a link to the Creative Commons licence, and indicate if changes were made. The images or other third party material in this article are included in the article's Creative Commons licence, unless indicated otherwise in a credit line to the material. If material is not included in the article's Creative Commons licence and your intended use is not permitted by statutory regulation or exceeds the permitted use, you will need to obtain permission directly from the copyright holder. To view a copy of this licence, visit http://creativecommons.org/licenses/by/4.0/. 


\section{References}

Alber F et al (2007) The molecular architecture of the nuclear pore complex. Nature 450:695-701. https://doi.org/10.1038/nature06405

Asim M, Hafeez BB, Siddiqui IA, Gerlach C, Patz M, Mukhtar H, Baniahmad A (2011) Ligand-dependent corepressor acts as a novel androgen receptor corepressor, inhibits prostate cancer growth, and is functionally inactivated by the Src protein kinase. J Biol Chem 286:37108-37117. https://doi.org/10.1074/jbc. M111.292771

Augereau P et al (2006) The nuclear receptor transcriptional coregulator RIP140. Nucl Recept Signal 4:e024. https://doi.org/10.1621/ nrs.04024

Augereau P, Badia E, Balaguer P, Carascossa S, Castet A, Jalaguier S, Cavailles V (2006) Negative regulation of hormone signaling by RIP140. J Steroid Biochem Mol Biol 102:51-59. https://doi. org/10.1016/j.jsbmb.2006.09.005

Aziz MH et al (2015) Suppressing NRIP1 inhibits growth of breast cancer cells in vitro and in vivo. Oncotarget 6:39714-39724. https ://doi.org/10.18632/oncotarget.5356

Bello JO, Nieva LO, Paredes AC, Gonzalez AM, Zavaleta LR, Lizano M (2015) Regulation of the Wnt/ $\beta$-catenin signaling pathway by human papillomavirus E6 and E7 oncoproteins. Viruses 7:47344755. https://doi.org/10.3390/v7082842

Boyer SN, Wazer DE, Band V (1996) E7 protein of human papilloma virus-16 induces degradation of retinoblastoma protein through the ubiquitin-proteasome pathway. Cancer Res 56:4620-4624

Calderon MR et al (2012) Ligand-dependent corepressor (LCoR) recruitment by Kruppel-like factor 6 (KLF6) regulates expression of the cyclin-dependent kinase inhibitor CDKN1A gene. J Biol Chem 287:8662-8674. https://doi.org/10.1074/jbc.M111.311605

Castet A et al (2004) Multiple domains of the receptor-interacting protein 140 contribute to transcription inhibition. Nucleic Acids Res 32:1957-1966. https://doi.org/10.1093/nar/gkh524

Cavailles V, Dauvois S, L'Horset F, Lopez G, Hoare S, Kushner PJ, Parker MG (1995) Nuclear factor RIP140 modulates transcriptional activation by the estrogen receptor. Embo J 14:3741-3751

Chellappan S, Kraus VB, Kroger B, Munger K, Howley PM, Phelps WC, Nevins JR (1992) Adenovirus E1A, simian virus 40 tumor antigen, and human papillomavirus E7 protein share the capacity to disrupt the interaction between transcription factor E2F and the retinoblastoma gene product. Proc Natl Acad Sci USA 89:45494553. https://doi.org/10.1073/pnas.89.10.4549

Chen HZ, Tsai SY, Leone G (2009) Emerging roles of E2Fs in cancer: an exit from cell cycle control. Nat Rev Cancer 9:785-797. https ://doi.org/10.1038/nrc2696

Christian M, Tullet JM, Parker MG (2004) Characterization of four autonomous repression domains in the corepressor receptor interacting protein 140. J Biol Chem 279:15645-15651. https://doi. org/10.1074/jbc.M313906200

Dimova DK, Dyson NJ (2005) The E2F transcriptional network: old acquaintances with new faces. Oncogene 24:2810-2826. https:// doi.org/10.1038/sj.onc. 1208612

Docquier A, Harmand PO, Fritsch S, Chanrion M, Darbon JM, Cavailles V (2010) The transcriptional coregulator RIP140 represses E2F1 activity and discriminates breast cancer subtypes. Clin Cancer Res 16:2959-2970. https://doi.org/10.1158/1078-0432.Ccr-09-3153

Drolet M, Benard E, Perez N, Brisson M (2019) Population-level impact and herd effects following the introduction of human papillomavirus vaccination programmes: updated systematic review and meta-analysis. Lancet 394:497-509. https://doi.org/10.1016/ s0140-6736(19)30298-3

Ferlay J et al (2019) Estimating the global cancer incidence and mortality in 2018: GLOBOCAN sources and methods. Int J Cancer 144:1941-1953. https://doi.org/10.1002/ijc.31937
Fernandes I et al (2003) Ligand-dependent nuclear receptor corepressor LCoR functions by histone deacetylase-dependent and -independent mechanisms. Mol Cell 11:139-150. https://doi.org/10.1016/ S1097-2765(03)00014-5

Frega A et al (2018) Preterm birth after loop electrosurgical excision procedure (LEEP): how cone features and microbiota could influence the pregnancy outcome. Eur Rev Med Pharmacol Sci 22:7039-7044. https://doi.org/10.26355/eurrev_201810_16176

$\mathrm{Fu} \mathrm{X}$ et al (2018) The rules and functions of nucleocytoplasmic shuttling proteins. Int J Mol Sci. https://doi.org/10.3390/ijms19051445

Ghoussaini M et al (2012) Genome-wide association analysis identifies three new breast cancer susceptibility loci. Nat Genet 44:312-318. https://doi.org/10.1038/ng.1049

Gupta S et al (2003) The human papillomavirus type 11 and 16 E6 proteins modulate the cell-cycle regulator and transcription cofactor TRIP-Br 1. Virology 317:155-164. https://doi.org/10.1016/j. virol.2003.08.008

Hester A et al (2019) The role of EP3-receptor expression in cervical dysplasia. J Cancer Res Clin Oncol 145:313-319. https://doi. org/10.1007/s00432-018-2785-3

Huq MD, Tsai NP, Lin YP, Higgins L, Wei LN (2007) Vitamin B6 conjugation to nuclear corepressor RIP140 and its role in gene regulation. Nat Chem Biol 3:161-165. https://doi.org/10.1038/ nchembio861

Jalaguier $\mathrm{S}$ et al (2017) Complex regulation of LCoR signaling in breast cancer cells. Oncogene 36:4790-4801. https://doi.org/10.1038/ onc. 2017.97

Lapierre M et al (2014) RIP140 increases APC expression and controls intestinal homeostasis and tumorigenesis. J Clin Invest 124:1899_ 1913. https://doi.org/10.1172/jci65178

Lapierre M, Docquier A, Castet-Nicolas A, Gitenay D, Jalaguier S, Teyssier C, Cavailles V (2015) The emerging role of the transcriptional coregulator RIP140 in solid tumors. Biochim Biophys Acta 1856:144-150. https://doi.org/10.1016/j.bbcan.2015.06.006

Lei JJ et al (2015) NOP14 suppresses breast cancer progression by inhibiting NRIP1/Wnt/beta-catenin pathway. Oncotarget 6:2570125714. https://doi.org/10.18632/oncotarget.4573

McNair C et al (2018) Differential impact of RB status on E2F1 reprogramming in human cancer. J Clin Invest 128:341-358. https:// doi.org/10.1172/JCI93566

Palijan A et al (2009a) Function of histone deacetylase 6 as a cofactor of nuclear receptor coregulator. LCoR J Biol Chem 284:30264 30274. https://doi.org/10.1074/jbc.M109.045526

Palijan A et al (2009b) Ligand-dependent corepressor LCoR is an attenuator of progesterone-regulated gene expression. J Biol Chem 284:30275-30287. https://doi.org/10.1074/jbc.M109.051201

Ramachandran B (2017) Functional association of oestrogen receptors with HPV infection in cervical carcinogenesis. Endocr Relat Cancer 24:R99-r108. https://doi.org/10.1530/erc-16-0571

Remmele W, Stegner HE (1987) Recommendation for uniform definition of an immunoreactive score (IRS) for immunohistochemical estrogen receptor detection (ER-ICA) in breast cancer tissue. Pathologe 8:138-140

Rosty C et al (2005) Identification of a proliferation gene cluster associated with HPV E6/E7 expression level and viral DNA load in invasive cervical carcinoma. Oncogene 24:7094-7104. https://doi. org/10.1038/sj.onc. 1208854

Scheffner M, Werness BA, Huibregtse JM, Levine AJ, Howley PM (1990) The E6 oncoprotein encoded by human papillomavirus types 16 and 18 promotes the degradation of p53. Cell 63:11291136. https://doi.org/10.1016/0092-8674(90)90409-8

Schiffman M, Wentzensen N (2013) Human papillomavirus infection and the multistage carcinogenesis of cervical cancer. Cancer Epidemiol Biomarkers Prev 22:553-560. https://doi. org/10.1158/1055-9965.Epi-12-1406 
Schiffman M, Wentzensen N, Wacholder S, Kinney W, Gage JC, Castle PE (2011) Human papillomavirus testing in the prevention of cervical cancer. J Natl Cancer Inst 103:368-383. https://doi. org/10.1093/jnci/djq562

Shalom-Barak T et al (2018) Ligand-dependent corepressor (LCoR) is a rexinoid-inhibited peroxisome proliferator-activated receptor $\gamma$-retinoid X receptor $\alpha$ coactivator. Mol Cell Biol. https://doi. org/10.1128/mcb.00107-17

Shreberk-Shaked M, Oren M (2019) New insights into YAP/ TAZ nucleo-cytoplasmic shuttling: new cancer therapeutic opportunities? Mol Oncol 13:1335-1341. https://doi. org/10.1002/1878-0261.12498

Srivastava P, Mangal M, Agarwal SM (2014) Understanding the transcriptional regulation of cervix cancer using microarray gene expression data and promoter sequence analysis of a curated gene set. Gene 535:233-238. https://doi.org/10.1016/j. gene.2013.11.028

Tainio K et al (2018) Clinical course of untreated cervical intraepithelial neoplasia grade 2 under active surveillance: systematic review and meta-analysis. BMJ 360:k499. https://doi.org/10.1136/bmj. k499

Triki M et al (2017) RIP140 and LCoR expression in gastrointestinal cancers. Oncotarget 8:111161-111175. https://doi.org/10.18632 /oncotarget.22686
Vattai A et al (2017) Investigation of RIP140 and LCoR as independent markers for poor prognosis in cervical cancer. Oncotarget 8:105356-105371. https://doi.org/10.18632/oncotarget.22187

Vo N, Fjeld C, Goodman RH (2001) Acetylation of nuclear hormone receptor-interacting protein RIP140 regulates binding of the transcriptional corepressor. CtBP Mol Cell Biol 21:6181-6188. https ://doi.org/10.1128/mcb.21.18.6181-6188.2001

Weinberg RA (1995) The retinoblastoma protein and cell cycle control. Cell 81:323-330. https://doi.org/10.1016/0092-8674(95)90385-2

White JH, Fernandes I, Mader S, Yang XJ (2004) Corepressor recruitment by agonist-bound nuclear receptors. Vitam Horm 68:123143. https://doi.org/10.1016/s0083-6729(04)68004-6

Wise-Draper TM, Wells SI (2008) Papillomavirus E6 and E7 proteins and their cellular targets. Front Biosci 13:1003-1017. https://doi. org/10.2741/2739

World Health Organization (2019) Human papillomavirus (HPV) and cervical cancer. https://www.who.int/news-room/fact-sheets/detai 1/human-papillomavirus-(hpv)-and-cervical-cancer. Accessed 9 Nov 2019

Publisher's Note Springer Nature remains neutral with regard to jurisdictional claims in published maps and institutional affiliations.

\section{Affiliations}

\section{Tilman L. R. Vogelsang ${ }^{1}$ - Elisa Schmoeckel ${ }^{3}$. Christina Kuhn ${ }^{1}$ - Thomas Blankenstein ${ }^{1} \cdot$ Mina Temelkov $^{1}$. Helene Heidegger ${ }^{1}$. Theresa Maria Kolben ${ }^{1} \cdot$ Thomas Kolben $^{1} \cdot$ Sven Mahner ${ }^{1}$. Doris Mayr ${ }^{3}$. Udo Jeschke ${ }^{1,2}$. Aurelia Vattai $^{1}$}

Tilman L. R. Vogelsang

ti.vogelsang@campus.lmu.de

Elisa Schmoeckel

elisa.schmoeckel@med.uni-muenchen.de

Christina Kuhn

christina.kuhn@med.uni-muenchen.de

Thomas Blankenstein

thomas.blankenstein@med.uni-muenchen.de

Mina Temelkov

mina.temelkov@med.uni-muenchen.de

Helene Heidegger

helene.heidegger@med.uni-muenchen.de

Theresa Maria Kolben

theresa.kolben@med.uni-muenchen.de

Thomas Kolben

thomas.kolben@med.uni-muenchen.de
Sven Mahner

sven.mahner@med.uni-muenchen.de

Doris Mayr

doris.mayr@med.uni-muenchen.de

Aurelia Vattai

aurelia.vattai@med.uni-muenchen.de

1 Department of Obstetrics and Gynecology, University Hospital, LMU Munich, 80337 Munich, Germany

2 Department of Obstetrics and Gynecology, University Hospital Augsburg, 86156 Augsburg, Germany

3 Institute of Pathology, Faculty of Medicine, LMU Munich, 80337 Munich, Germany 